\title{
LA CRISIS DEL POSITIVISMO JURÍDICO: KELSEN, HART, BOBBIO
}

\section{Cristóbal Orrego Sánchez}

Profesor de Filosofía Jurídica y Política

Universidad de los Andes

El positivismo jurídico, en sus múltiples formas, ha sido la visión dominante del derecho a partir del siglo $X I X .{ }^{1}$ Sin embargo, desde mediados del siglo $X X$ ha sufrido una transformación tan radical que algunos autores dudan de la conveniencia de seguir utilizando esa denominación. De hecho, la mentalidad iuspositivista es una de las claves de comprensión de nuestra actual cultura jurídica, razón por la cual no conviene olvidar la historia de esta tradición intelectual. En este artículo presentaremos los rasgos fundamentales del positivismo jurídico — de "algunos" positivismos jurídicos-y procuraremos mostrar tres intentos de superar la crisis del positivismo jurídico a principios de este siglo y, especialmente, a partir de 1945.

\section{1. ¿Qué es el positivismo jurídico?}

Nadie está en condiciones de dar una sola definición de "positivismo jurídico". De hecho, las conceptualizaciones de Hart y Bobbio - posteriores a la segunda guerra mundial - buscan deslindar los postulados conflictivos - incluso inaceptables - de algunas posiciones denominadas iuspositivistas respecto de otras tesis más aceptables que permitan mantener en pie la tradición iuspositivista. En consecuencia, para compreder la historia del positivismo jurídico y de sus múltiples conceptualizaciones, vamos a describir primero el denominado "positivismo jurídico legalista" de la Escuela de la exégesis. En los apartados siguientes presentaremos una síntesis de los intentos notables de Kelsen, Hart y Bobbio, de superación del positivismo legalista sin una vuelta clara y neta a los postulados clásicos del iusnaturalismo pre-moderno.

\subsection{El legalismo de la Escuela de la exégesis}

El proceso de codificación fue impulsado por el iusracionalismo del s. XVIII, que aceptaba de manera general la existencia de unos principios racionales como fuente y fundamento de todo derecho, principios universales cognoscibles por todos los seres humanos y capaces de proporcionar de manera deductiva las soluciones concretas a todos los problemas planteables en la vida social. Sólo faltaba poner por escrito, en una ley estatal clara y unificadora del derecho, los postulados del Derecho Natural. A eso

1 Cfr. HERVADA Javier. Historia de la ciencia del derecho natural (Pamplona, Eunsa, 2a ed., 1991), pp. 311 y ss. 
venían los códigos. En el debate sobre la codificación se contrapusieron las teorías racionalistas, que confiaban en poder reducir el derecho disperso a la unidad de la ley y en limitar la arbitrariedad judicial mediante la claridad de un derecho nuevo, y las teorías de corte historicista más respetuosas del genio propio de cada pueblo y, sobre todo, más confiadas en una labor de clarificación científica del derecho y no de unificación "desde arriba" por obra de la ley. En definitiva, la corriente codificadora triunfó ampliamente en el ámbito francés, español e hispanoamericano. De ahí que nuestra cultura jurídica, tan apoyada en la francesa y, algo más tarde, en la española, heredara los rasgos de la posición dominante a partir de la codificación francesa.

La escuela de la exégesis (1830-1880) concebía el estudio del derecho como un estricto comentario del código, interpretado "literalmente" y siguiendo la sistemática y los conceptos elaborados por el legislador. "Yo no conozco el derecho civil, yo enseño el código de Napoleón" (Juan José Bugnet, 1794-1886). ${ }^{2}$ Los primeros codificadores (v.gr. Portalis) creían en un "derecho natural" racional como trasfondo de todo derecho positivo. En cambio, una vez realizada la codificación, con su reducción de todo derecho a la ley estatal, con su ideal de "certeza" del derecho y de separación de poderes con un juez concebido como "la boca muerta que pronuncia las palabras de la ley" (Montesquieu), los juristas comenzaron a considerar que el fundamento de la validez de las normas es precisamente el hecho de emanar de la voluntad del legislador, i.e. que estén recogidas en el código.

Los teóricos de la escuela de la exégesis, sin negar la existencia de un "derecho natural", lo hacen en la práctica superfluo.

La escuela de la exégesis dará origen, así, a un modo de pensar, corrientemente denominado "positivismo legalista", que (i) reduce todo el derecho a la ley: (ii) asimila el sistema jurídico a un sistema lógico formal (matemático) (a) completo - sin lagunas-, (b) coherente - sin antinomias - y (c) claro — sin oscuridades; (iii) donde el juez, sometido a la ley, sólo aplica a los hechos conocidos las reglas positivas para obtener la sentencia (método de la subsunción); y (iv) donde el jurista dogmático ("la doctrina") se ha de limitar a proporcionar los "conceptos" jurídicos fundamentales inducidos del sistema creado por el legislador. Si el texto de la ley no fuese claro, habría que interpretarlo, para lo cual se ha de buscar la voluntad histórica del legislador. ${ }^{3}$

Junto al legalismo de la escuela de la exégesis, y por la misma época e incluso antes, se plantea una forma de "positivismo jurídico" que tiene por objeto obtener la obediencia absoluta de los ciudadanos y de los jueces al legislador, bajo el pretexto de que la opinión subjetiva sobre su justicia o injusticia se ha de someter al criterio objetivo y determinable establecido en la ley. En síntesis, la incapacidad para determinar con certeza una solución basada en criterios de justicia, y la necesidad de conseguir esa

2 Cfr. FASSÒ Guido, Historia de la Filosofía de Derecho. Vol. 3. Siglos XIX y XX (Madrid, Ed. Pirámide, 5a ed,
1988), p. 25.
3 Cfr. PERELMAN Chäim, La lógica juridica y la nueva retórica (Madrid, Civitas, 1979), pp. 35-71. 
certeza para una pacífica convivencia, obligan a tener como "derecho" lo establecido en la ley. "La ley es la ley".

\subsection{La crisis del legalismo}

El positivismo legalista entró en crisis ya a fines del siglo XIX en Europa. Entre 1890 y 1945 tuvieron su apogeo las escuelas funcionalistas, teleológicas y sociológicas del derecho. Las orientaciones mencionadas han abandonado los dogmas de la "plenitud", "claridad" y "coherencia" del ordenamiento jurídico, para proponer medios de llegar a una solución jurídica que no se "deduce" de premisas generales claras. Entonces se recurre a la "voluntad del legislador", real o presunta o ficticia. Las tesis funcionales y sociológicas sostienen que el derecho sólo se comprende a la luz de un fin buscado por el legislador y a la luz del contexto social en que existe la norma. Como el contexto social cambia, los juristas y los jueces acuden a presunciones y ficciones jurisprudenciales que dan a las normas un sentido nuevo adaptado a las necesidades o exigencias de la solución que se considera "justa". De más está decir que estas formas de arribar a la justicia se oponen a los ideales de certeza jurídica y de sumisión de los jueces al poder legislativo; es decir, contravienen los dogmas de la racionalidad sistemática del derecho y de la separación de los poderes públicos. ${ }^{4}$

Por su parte, el legalismo que exigía la obediencia ciega a la ley —aún sacrificando la conciencia, como dice con fuerza Karl Bergbohm (1849-1927) - , que tenía tras de sí los fundamentos no despreciables del pensamiento hobbesiano, entró claramente en crisis a partir de 1945. El argumento conocido como "reductio ad hitlerum" vino a culpar al positivismo jurídico legalista - y al funesto eslogan "la ley es la ley" de la facilidad con que el estamento jurídico, político y académico, se plegó a la ideología totalitaria del nacionalsocialismo. La situación, como ha mostrado lúcidamente Arendt, no puede explicarse tan cómodamente. Sin embargo, la llamativa conversión de Radbruch desde su positivismo jurídico fundado en el relativismo ético a una posición de objetivismo moral, que preconizaba un derecho por encima de las leyes estatales, junto con la necesidad de recurrir a argumentos "iusnaturalistas" para flexibilizar el principio de legalidad penal y castigar así los crímenes autorizados - y aún exigidospor el estado nacionalsocialista, llevaron a una efectiva crisis de prestigio del "positivismo jurídico". 5

A partir de 1945, los autores que pretendían sostener la tradición iuspositivista tuvieron que contar una historia nueva sobre el positivismo jurídico, una historia que lo limpiara del estigma de "totalitarismo", en verdad injusto y simplista. Además, se vieron en la necesidad de proporcionar explicaciones más realistas del derecho, para superar la crisis interna de la mentalidad exegética y del conceptualismo de la teoría general

4 Ibid., pp. 72-91.

5 Cfr. la descripción de HART, "Positivism and the Separation of Law and Morals", en Essays in Jurisprudence and Philosophy (Oxford, O.U.P., 1983), pp. 72-74. Hart constató la crisis del positivismo jurídico y procuró — con bastante éxito - remontarla. 
del derecho decimonónica. Entre los autores que, en menos de medio siglo, dieron vuelta la imagen del positivismo jurídico - esa imagen académica tanto como la popular-. hasta ponerlo de nuevo en una posición dominante como tradición de pensamiento jurídico — vaciada de sus tesis sustanciales más fuertes-, destacan Hans Kelsen, H.L.A. Hart y Norberto Bobbio.

\section{El positivismo jurídico según Kelsen, Hart y Bobbio}

Hans Kelsen, Herbert L.A. Hart y Norberto Bobbio, tres de los más destacados y coherentes filósofos o teóricos del derecho en el siglo $\mathrm{XX}$, procuraron ofrecer sendas descripciones de la tradición del positivismo jurídico y, al mismo tiempo, una explicación de la realidad jurídica — cada uno la suya propia, diversa de la de los otros-compatible con esa definición previa del enfoque iuspositivista. Recordaremos sucintamente las principales tesis de estos autores sobre el tema propuesto. Los tres se caracterizan por defender alguna forma de iuspositivismo por razones, al menos en parte, de rigor científico en el estudio del derecho. Yo procuraré mostrar que, además de la preocupación por la cientificidad en el estudio del derecho, hay razones morales y políticas subyacentes a esa opción por una tradición que estaba en crisis y que necesitaba ser revitalizada. Sostendré, además, que esa revitalización del positivismo jurídico fue posible merced a una genuina transformación de la tradición, unida a un abandono de las tesis más opuestas a la teoría clásica del derecho natural (por "clásica" entiendo la que se inspira sobre todo en Aristóteles, no el iusnaturalismo racionalista del siglo XVIII).

\subsection{Hans Kelsen (1881-1973)}

La tesis central del positivismo jurídico kelseniano es que la validez del derecho positivo no puede depender de su relación con la justicia (separación del derecho y la moral) porque (i) no existe un ser trascendente capaz de originar con su voluntad normas absolutas y heterónomas respecto de los seres humanos (agnosticismo y ateísmo) y (ii) no existe, en consecuencia, ningún valor moral absoluto (relativismo ético). Kelsen defiende explícitamente un "positivismo jurídico relativista", pues precisamente el carácter relativo y subjetivo de los principios morales, tan contrapuestos entre unos hombres y otros, hace necesario excluir tales juicios de valor de un estudio científico, objetivo y riguroso, del derecho como orden normativo coactivo generalmente eficaz en un determinado tiempo y lugar. Kelsen no niega la existencia de criterios de justicia que podrían servir a cada uno - incluido a quien, como él, defiende el iuspositivismo- para juzgar y criticar el derecho; simplemente sostiene que esos criterios son relativos, nunca absolutos, y que dependen de los sentimientos subjetivos de cada uno. Por eso, una ciencia compartida del derecho necesita excluir esas referencias valorativas. De la misma manera, una defensa coherente de la democracia como régimen político exige fundarla en el relativismo ético, que excluye toda imposición de un valor como si fuese absoluto. Se entiende que Kelsen vea en el escepticismo de Pilatos, al juzgar a Jesucristo, el modelo de decisión democrática, que rehúsa imponer su propia opinión sobre el caso para acoger la decisión del pueblo. 
En conformidad con esa concepción del positivismo jurídico, pero consciente de la crisis del legalismo y del formalismo, Kelsen elabora una explicación del derecho que al mismo tiempo supera algunas de las deficiencias del legalismo, suaviza el formalismo lógico - mediante la combinación de actos cognoscitivos del derecho y actos volitivos de creación jurídica dentro de un marco - y conserva la orientación avalorativa en la ciencia del derecho.

Las tesis principales del pensamiento jurídico de Kelsen son (i) la separación serdeber como primer principio; (ii) la identificación y estudio del derecho positivo como único objeto de la ciencia jurídica (pureza metódica total); (iii) la explicación del sistema jurídico como orden normativo coactivo, donde la validez de las normas se funda en su creación conforme a una norma superior - cualquiera sea su contenido- hasta la afirmación de una norma fundamental hipotética o ficticia ("uno debe comportarse como la Constitución lo prescribe"), supuesta como condición - no como causa o fundamento - la general eficacia del sistema y de cada norma (teoría de la estructura jerárquica del ordenamiento: Grundnorm, Constitución, normas jurídicas generales ley, costumbre y precedentes - normas individuales - sentencias, negocios, actos administrativos- y ejecución del acto coactivo); (iv) la rígida separación entre el derecho y la moral como órdenes normativos positivos, donde el criterio de distinción es en último término el carácter coactivo del derecho (el derecho es la norma primaria que impone la sanción coactiva o un orden coactivo que impone sanciones); ( $v$ ) la negativa de la teoría anti-ideológica (pura) del derecho a juzgar axiológicamente el derecho (positivo), pues todo lo que va más allá del dominio de las ciencias positivas es "ideológico" y pertenece al reino de la irracionalidad (la justicia es un ideal irracional), de los intereses que provienen sólo de un querer subjetivo; (vi) el antilegalismo y antiformalismo en la teoría de la interpretación y aplicación del derecho: la sentencia nunca es meramente declarativa, sino que es siempre constitutiva del derecho (decisionismo judicial en el marco de las reglas generales: la función cognoscitiva determina el marco y la función exclusivamente volitiva selecciona la posibilidad); (vii) la identificación del estado y el derecho, de modo que todo estado es "estado de derecho" (contra el prejuicio iusnaturalista); (viii) la concepción del derecho nacional junto con los derechos estatales como un sistema unitario de normas (con la tesis de que la primacía de uno u otro son dos hipótesis igualmente válidas para la ciencia del derecho, pero inclinado a preferir la primacía del derecho internacional por razones de unificación política de mundo). ${ }^{6}$

\subsection{H.L.A. Hart (1907-1992)}

H.L.A. Hart caracterizó el positivismo jurídico y elaboró una teoría del derecho que superaba algunas de las tesis iuspositivistas, retornando a posiciones clásicas en el sentido ya precisado. A continuación veremos su caracterización del "positivismo jurí-

Sobre lo expuesto en relación con Kelsen, cfr. ERRÁZURIZ Carlos José, Introducción crítica a la doctrina jurídica de Kelsen (Santiago, Ed. Jurídica de Chile, 1987), passim, y HERRERA Hugo, "Democracia y relativismo en Hans Kelsen", lus Publicum 2, 1999, pp. 29-47. 
dico" y, en seguida, los rasgos principales de su concepto de derecho renovado mediante algunas intuiciones de la filosofía analítica del lenguaje.

Hart caracterizó el "positivismo jurídico" enumerando las tesis que en diversos períodos han sido calificadas como "positivistas", es decir, dando una "definición en uso" de acuerdo con los significados que la expresión ha revestido para diferentes autores. De esas tesis, Hart acepta sólo las que considera esenciales para conservar la tradición iuspositivista. En otro lugar ${ }^{7}$ he identificado diez tesis positivistas: (1) la teoría imperativa del derecho (consiste en mandatos del soberano o en mandatos de seres humanos); (2) el voluntarismo jurídico, en un sentido más amplio que (1); (3) la tesis de las fuentes sociales del derecho; (4) la tesis de la separación conceptual entre el derecho y la moral, en el sentido de que, no obstante las muchas conexiones entre moral y derecho, las referencias a la justicia no entran en su definición y el derecho injusto sigue siendo válido; (5) la teoría positivista semántica; (6) la tesis del análisis conceptual no valorativo del derecho (separación de descripción y crítica de los sistemas y reglas de derecho); (7) el no cognitivismo ético (relativismo, subjetivismo y/o escepticismo moral); (8) la tesis logicista sobre la aplicación judicial del derecho ("jurisprudencia mecánica"), que deduce la única solución jurídica de las reglas pre-existentes aplicadas de manera lógica; (9) la tesis de la discrecionalidad judicial (el juez crea discrecionalmente el derecho en las áreas no definidas por las reglas generales), que se opone a (8); y (10) la tesis del deber moral absoluto de obedecer el derecho.

Hart rechazó las tesis (1), (2), (8) y (10), y aceptó las tesis (3), (4), (5), (6) y (9). La tesis (7) no requiere de un pronunciamiento, pues son compatibles tanto con el positivismo como con su negación; sin embargo, en el ámbito de sus opiniones morales - separadas de su ciencia jurídica- Hart se inclina por alguna forma de no cognitivismo ético, e incluso, hacia el final de su obra, por una suerte de teoría no cognitivista sobre el derecho mismo. Sólo son "esenciales" las tesis (3). (4), y (6). Según Hart, el positivismo jurídico se ha de adoptar, en su versión mínima, por razones de claridad científica, que exige considerar como válido también el derecho inicuo, y de honestidad moral, porque, incluso para resistir el derecho inicuo, antes habría que identificarlo "avalorativamente". ${ }^{8}$

El concepto de derecho elaborado por Hart concibe las reglas del derecho como razones para la acción, no vinculadas al mandato de un soberano, sino existentes como pautas de conducta con diversas funciones que forman un sistema unitario en virtud del reconocimiento de los funcionarios - especialmente los jueces- y de los ciudadanos, cuya práctica de reconocimiento, que es un hecho social complejo, constituye una regla para la identificación de las demás reglas válidas del sistema, incluidas las reglas de judicación y de cambio de las reglas. El sistema que así resulta está formado por reglas primarias - de obligación o de conducta - y por reglas secundarias - de reconocimiento, cambio y judicación, y las que confieren potestades públicas y privadas-, todas las

\footnotetext{
${ }^{7}$ ORREGO Cristóbal, H.L.A. Hart. Abogado del positivismo jurídico (Pamplona, Eunsa, 1997), pp. 16 y ss.

${ }^{8}$ Cfr. H.L.A. HART, The Concept of Law (Oxford, O.U.P., 1961), capitulo IX.
} 
cuales tienen el aspecto externo que puede observar un sociólogo, las regularidades de conducta, y el aspecto interno o "normativo" que sólo reconoce quien las ve funcionar como razones y justificaciones de la acción, de las sanciones, del reproche por el incumplimiento, etc. ${ }^{9}$

\subsection{Norberto Bobbio $(1909-)$}

Hans Kelsen tiene una concepción clara del "positivismo jurídico" como esencialmente normativista - el derecho consiste en normas que establecen un deber ser separado de los hechos empíricos-y axiológicamente relativista. Todo su esfuerzo se dirigió a reformular los conceptos jurídicos y la sistemática jurídica de manera que fuese posible una exposición puramente científica del derecho, sin reducir la ciencia jurídica ni a ciencia empírica (v.gr., la sociología jurídica) ni a ideología (moral, religión, metafísica, etc.). H.L.A. Hart, en cambio, definió de manera múltiple el positivismo jurídico, de modo que, en realidad, casi cualquier postura históricamente relevante en la teoría del derecho puede hacerse compatible con alguna o algunas de las tesis positivistas. Norberto Bobbio, por último, fue quien caracterizó el positivismo jurídico con más detalle y con mayor conocimiento histórico, a la par que detectó las razones de su crisis y fue capaz de salvar la tradición renunciando a algunos de sus elementos tradicionales. A continuación veremos su caracterización del positivismo jurídico y algunas tesis sobre el derecho defendidas como compatibles con el iuspositivismo metodológico.

"El positivismo ha muerto. ¡Viva el iusnaturalismo!", decía Bobbio en una famosa mesa redonda sobre el positivismo jurídico (Pavía, 1966). Sin embargo, lo cierto es que Bobbio presenta una conceptualización compleja del positivismo jurídico y se mantiene dentro de esa tradición. Según Bobbio, hay tres maneras de entender el iuspositivismo: (i) un modo de aproximación al estudio del derecho (positivismo metodológico); (ii) una teoría del derecho como producto del poder estatal (positivismo teórico estatalista), y (iii) una ideología de la obediencia debida al poder político (positivismo ideológico).

El positivismo metodológico o conceptual sostiene que se ha de distinguir el concepto de derecho del concepto de moral, con el fin de poder aproximarse de manera científica al estudio y descripción del derecho positivo "tal como es", prescindiendo de la opinión subjetiva de cada uno acerca de cómo "debe ser" el derecho. Bobbio se declara "positivista metodológico" porque ese método o aproximación al derecho es la única actitud científica: "Así como la ciencia o es avalorativa o no es ciencia, el método positivista es pura y simplemente el método científico, y por lo tanto es necesario adop-

9 Cfr. ibid., capítulos IV, V y VI. Una visión sintética en ORREGO Cristóbal, "El giro lingüístico en la filosofia y la jurisprudencia analítica de H.L.A. Hart", Revista de Derecho. Universidad Católica del Norte, 1996, pp. 5559. 
tarlo si se quiere hacer ciencia jurídica o teoría de derecho". ${ }^{10}$ Esta postura iuspositivista - salta a la vista su parecido con la tesis hartiana de la separación conceptual entre el derecho y la moral- sería compatible con cualquier teoría más amplia sobre el derecho en su relación con el estado y el poder y con cualquier ideología sobre los valores que deben reflejarse en el derecho. Así, Bobbio puede sentirse iuspositivista como científico y iusnaturalista como defensor de los valores sustantivos expresados en los derechos humanos (fundados de manera relativa en el consenso cultural).

El positivismo como teoría del derecho agrupa seis tesis que, no obstante sus interconexiones, podrían sostenerse o refutarse por separado: (1) la tesis coactiva (el derecho procede del poder coactivo del estado como fuente social, y no de una fuente racional o divina); (2) la tesis imperativa (el derecho consiste en el mandato de una voluntad que establece deberes); (3) la tesis legalista (el derecho se reduce, de una u otra manera, a la ley del estado); (4) la tesis de la plenitud del ordenamiento jurídico (los problemas jurídicos encuentran solución en las normas del ordenamiento positivo, de modo que no hay verdaderas lagunas en el derecho); (5) la tesis de la coherencia del ordenamiento jurídico (el sistema contiene normas no contradictorias o, dicho de otra manera, no puede haber normas simultáneamente válidas que se contrapongan), y (6) la tesis de la aplicación mecánica o logicista de las normas (el juez no crea derecho).

El positivismo ideológico, por su parte, sostiene que el derecho positivo debe ser obedecido con independencia de su contenido, por el bien de la paz social, de la seguridad jurídica y del orden público. El positivismo ideológico extremo sostiene que todo contenido del derecho es justo, pues antes del establecimiento de la ley por el estado no existen los criterios objetivos a la luz de los cuales puede afirmarse que una conducta es justa o injusta. El positivismo ideológico moderado sostiene que, aunque el derecho puede ser injusto según un criterio ético determinado, de todas formas existe en general al obligación moral de obedecerlo en aras de un bien superior (la convivencia pacífica, etc.).

Bobbio reconoce que las tesis de la plenitud y coherencia del ordenamiento jurídico - tan caras a la escuela de la exégesis - han sido refutadas, como lo ha sido asimismo la concepción logicista de la aplicación de derecho. Además, desde 1945 nadie osa defender un positivismo ideológico como tesis de la obediencia debida a "la ley" por el solo hecho de ser "la ley". En todo caso, se dice que la exigencia de obedecer sólo puede provenir de la moral y su consideración como exigencia jurídica ha sido precisamente el error de cierto tipo de iusnaturalismo. En definitiva, Bobbio logra despojar a la tradición iuspositivista de las tesis inaceptables de la teoría del derecho y de la ideología positivista; pero siguen siendo aceptables las tesis imperativa, coactiva y legalista. Ahora bien, el positivismo jurídico como tradición podría despojarse incluso de estas tres últimas tesis - rechazar el imperativismo, el legalismo y la tesis de las fuentes sociales coactivas del derecho- y conservar simplemente la afirmación metodológica

10 BOBBIO Norberto, II positivismo giuridico (Torino, Giappichelli, 1979 [1961]), p. 285, cit. por BARRĖRE UNZUETA María Ángeles, La escuela de Bobbio (Madrid, Tecnos, 1990), p. 45 .. 
de que la "ciencia jurídica" en cuanto tal ha de permanecer ajena a la valoración del derecho, valoración que será posible posteriormente en otra sede (moral, ideológica, etc.).

La matriz metodológica positivista o "positivismo jurídico conceptual" se hace compatible en Bobbio con una explicación del derecho positivo que ha evolucionado desde una etapa (años 50-60) en que defendió una teoría general del derecho formal y avalorativa, interesada en la estructura del derecho y bastante inspirada en los ideales de pureza metódica de Kelsen (separación del estudio normativo jurídico respecto de las valoraciones morales subjetivas y los análisis sociológicos), a otra etapa (fines de los 60 y años 70 hasta el presente) en que defiende un análisis funcional del derecho, que va más allá de la estructura para centrarse en las funciones y los "fines" del derecho. El análisis funcional del derecho vuelve a "contaminar" — según la perspectiva kelseniana- el estudio científico del derecho con las perspectivas sociológicas, antropológicas e ideológicas (Bobbio reconoce la influencia antiformalista de los muchos "marxismos" en las explicaciones sobre el derecho). Naturalmente, el análisis funcional del derecho lleva como de la mano hacia planteamientos - y aún los exige- acerca de los fines del derecho, de los valores que pueden ser servidos por el derecho y del carácter más o menos objetivo o subjetivo, absoluto o relativo, de esos fines y valores.

En este contexto podemos enumerar algunas observaciones de Bobbio sobre las funciones del derecho, que parecen compatibles con el iuspositivismo metodológico a la vez que implican referencias superadoras de los demás aspectos del positivismo jurídico, precisamente por la recuperación de la visión teleológica del derecho. El análisis de Bobbio distingue las siguientes funciones del derecho (según los criterios de clasificación señalados entre paréntesis): $:^{11}$ (1) función represiva-protectora y función promocional (modo de controlar comportamientos); (2) función indicadora para el ejercicio del poder coactivo: cuándo, cómo, cuánto y quién ejerce la fuerza coactiva (el derecho regula el uso de la fuerza); (3) función modeladora de la sociedad por el derecho, que puede ser autosuficiente o limitada; (4) función preventiva y función represiva (oportunidad en que actúa el ordenamiento jurídico); (5) función positiva, negativa y disfunción (si se alcanzan o no los fines propuestos por el derecho); (6) función privatista y función comunitaria (en cuanto el derecho contiene normas de conducta dirigidas a que cada uno obtenga sus fines privados y normas de organización que hacen posible la cooperación dirigida a un fin común); (7) función de control -mediante sanciones en sentido amplio- y función de dirección hacia fines - mediante normas técnicas que indican la vinculación entre determinados medios y los fines a que ellos llevan según el derecho; (8) función aseguradora y función distributiva (en cuanto se usa el derecho no sólo para garantizar posiciones sino también para cambiarlas mediante la asignación de recursos económicos y no económicos). Este análisis funcional del derecho viene a complementar el análisis estructural; pero, en la medida en que abre la ciencia jurídica a los fines, transgrede los límites de la pureza "científica" preconizada por el positivis-

11 Síntesis tomada de VIGO Rodolfo Luis, Perspectivas iusfilosóficas contemporáneas (Buenos Aires, AbeledoPerrot, 1991), pp. 141-146. 
mo metodológico "puro". Bobbio termina incluyendo en la ciencia jurídica las temáticas morales y políticas, como, por ejemplo, el problema de la paz como fin del derecho. Sin embargo, su posición ética no cognitivista le lleva a defender el valor instrumental del derecho en servicio del orden y de la paz, que exigen obediencia por regla general con independencia del contenido de las normas (positivismo ideológico moderado, compatible con su iusnaturalismo ideológico y su adhesión a una teoría débil de los derechos humanos).

\section{Conclusión}

Los autores posteriores a la segunda guerra mundial abandonaron la mayor parte de las tesis iuspositivistas clásicas, que dependían de la filosofía política de la división de los poderes y la soberanía popular, para dejar fuera del positivismo jurídico las tesis morales sobre el deber de obedecer el derecho. Kelsen retiene el relativismo ético como pieza esencial de una posición iuspositivista "científica"; pero abandona los dogmas legalistas y reconoce la creatividad judicial. Hart, a su vez, abandona incluso el relativismo ético como parte esencial del positivismo jurídico, de manera que hace compatible su nuevo iuspositivismo incluso con las tesis más fuertes del objetivismo ético iusnaturalista. Bobbio, por último, también desmembra el "positivismo jurídico" de tal manera que puede aceptar las refutaciones de muchas tesis particulares - refutaciones académicas $\mathrm{y} / \mathrm{o}$ políticas - $\sin$ abandonar por eso los pilares de la tradición iuspositivista.

Desde el punto de vista clásico, la evolución contemporánea del positivismo jurídico equivale a un vaciamiento de sus tesis fuertes — precisamente las exigidas por la crisis violenta del consenso religioso y moral en Occidente- para retener la cáscara de una denominación que hace viable seguir en la trinchera opuesta a la tradición del derecho natural. A ella se retorna en muchos puntos de fondo, que equivalen a reconocer que el criterio fenomenológico del positivismo jurídico reclama un fundamento metafísico: pasar del fenómeno al fundamento. ${ }^{12}$ Este retorno de hecho a algunas tesis clásicas no es compatible con reconocerlo abiertamente, porque va unido a una negación del derecho natural, ya tradicional en el seno de cierto pensamiento tardomoderno.

\footnotetext{
${ }^{12}$ Cfr. Juan Pablo II, Litt. Enc. Fides et ratio, 14-IX-1998, n. 83.
} 